Exposure (skin and/or

mucosal changes)

- Skin changes are often the first feature, and are present in over $80 \%$ of anaphylactic reactions

- Skin changes can be subtle or dramatic

- There may be erythema (a patchy or generalised red rash)

- Urticaria (hives, nettle rash, weals or welts)

- Angioedema (similar to urticaria but involves swelling of the deeper tissues such as the eyelids, lips, mouth or throat)

- Cyanosis - a late sign!

\section{What is the treatment?}

- Intramuscular adrenaline

- Oxygen (highest flow rate with a nonrebreather mask and reservoir)

- Call 999/112 (must go to hospital, even if apparently recovered)

\section{Intramuscular adrenaline (IM doses of 1:1000 adrenaline)}

\begin{tabular}{l|l}
\hline Adult: & 500 micrograms IM $(0.5 \mathrm{~mL})$ \\
\hline Child more than 12 years: & 500 micrograms IM $(0.5 \mathrm{~mL})$ \\
\hline Child 6-12 years: & 300 micrograms $I M(0.3 \mathrm{~mL})$ \\
\hline Child less than 6 years: & 150 micrograms IM $(0.15 \mathrm{~mL})$ \\
\hline
\end{tabular}

'Repeat the dose if there is no improvement in the patient's condition. Further doses can be given at about five minute intervals according to the patient's response' (www.resus.org.uk).

'Patients with airway and breathing problems may prefer to sit up as this will make breathing easier. Lying flat with or without leg elevation is helpful for patients with a low blood pressure. If the patient feels faint, do not sit or stand them up - this can cause cardiac arrest. Patients who are breathing and are unconscious should be placed on their side (recovery position). Pregnant patients should be placed on their left side to prevent caval compression' (www.resus.org.uk).

\section{Auto-injectors}

- EpiPen www.epipen.co.uk

- Anapen www.anapen.co.uk

- Jext www.jext.co.uk

- Anapen, EpiPen and Jext have an expiry alert service by email or text messaging

- For self-use by patients or carers

- Anyone who has an adrenaline injector should also have a training device to practise with

- Train the patient and carers in using the device (their use is not intuitive)

- Only $30 \%$ of patients know how and when to use their injector; have one that is in date, and carry it all the time.
'After emergency treatment for suspected anaphylaxis, offer people an adrenaline injector as an interim measure.'
Frequency and reporting

of anaphylaxis

The following is an extract from the NICE guideline published 14 December 2011 as reported by the Anaphylaxis Campaign www.

'Because of inconsistencies in reporting anaphylaxis, and because it is often misdiagnosed, there is no overall figure for the frequency of anaphylaxis from all causes in the UK ... there are now around 20 deaths each year in the UK from anaphylaxis (although this may be a substantial underestimate) ... in addition, there is considerable geographic variation in both practice and service provision...'

\section{Recommendations from the new guideline include:}

- Record the circumstances immediately before the onset of the reaction to help to identify the possible trigger

- After emergency treatment for suspected anaphylaxis, offer people (or, as appropriate, their parent and/or carer) an appropriate adrenaline injector as an interim measure before the specialist allergy service appointment.

Lynne Regent, CEO of the Anaphylaxis Campaign says: 'The Anaphylaxis Campaign welcomes the NICE guidelines as we believe it is important for all patients who have had emergency treatment for suspected anaphylaxis to be offered a referral to a specialist who can accurately diagnose and manage their condition. We also welcome the recommendation that patients should be given an adrenaline auto-injector before discharge, to ensure that they are equipped in the event of subsequent reactions.'

\section{Useful websites}

Resuscitation Council (UK)

www.resus.org.uk

Anaphylaxis Campaign

www.anaphylaxis.org.uk anaphylaxis.org.uk:

- Panic attack - victims of previous anaphylaxis may be particularly prone to panic attacks if they think they have been re-exposed to the allergen

- Breath holding in children

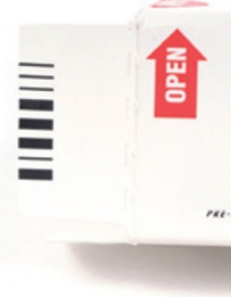
$\square$ Adrenaline (Epinephrine) Injection 1:1000

- Idiopathic (ie without a

known cause) (non-

allergic) urticaria or angioedema.

If in doubt - treat as anaphylaxis!

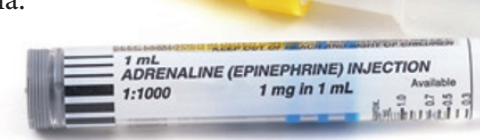

